\title{
Effect of Pretreatment on Crushing Process of Waste Phone's Circuit Boards by Mechanical-physical Method
}

\author{
Hongjun LIU ${ }^{a}$, Zhengdong $\mathrm{QI}^{\mathrm{b}}$ \\ State Key Laboratory of Advanced Processing and Recycling of Non-ferrous Metals, Lanzhou \\ University of Technology, Lanzhou 730050, China \\ aemail: hongjun_liu@hotmail.com, bemail: 825842319@qq.com
}

Keywords: Waste Phone's Circuit Board; Crushing; Liberation; Pretreatment; Mechanical-physical Method

\begin{abstract}
The crushing effect of waste phone's circuit boards by mechanical-physical method under different pretreatment processes (without pretreatment, disassembling electrical components, heating treatment) was investigated. The composition, mass distribution, feature, liberation degree of crushed products were analyzed. The results show that the heating process has the obvious influence on the mass distribution and disassembling has almost no effect on the crushing effect. The liberation is easiest for the circuit boards after heating and is difficult for the circuit boards after disassembling. Considering the impact of environment and investment, the waste phone's circuit boards can be directly crushed without disassembling and heating treatment.
\end{abstract}

\section{Introduction}

As the smartphone market booms, a huge number of mobile phones become obsolete every year, and the same amounts of the waste phone's circuit boards have been generated. On the one hand, abundant toxic materials including heavy metals can easily be found in the waste phone's circuit boards and can cause enormous damage to the environment [1]. On the other hand, a lot of valuable materials can be found in the waste phone's circuit boards, and its recycling value is very high. Quite similar to the waste PCBs of computers, the components of waste phone's circuit boards can be divided into metallic fractions and nonmetallic fractions. The metallic fractions, about $30 \%$, is composed of $\mathrm{Cu}(\sim 16 \%)$, Sn ( 4\%), Fe ( 3\%), Ni ( 2\%), Pb ( 2\%), Zn ( 1\%), Ag (0.05\%), Au (0.03\%), Pd (0.01\%), and other metals (Bi, Sb, Ti, etc. $<0.01 \%)$ [2,3]. So it is necessary to properly treat the waste phone's circuit boards, especially to recycle the valuable materials. A lot of works are being undertaken to investigate every step of the recycling.

In general, the waste phone's circuit boards consist of a heterogeneous mix of organic materials, metals, glass fibers, etc. The recycling methods mainly include physical, chemical, or biological methods or a combination of these approaches [4]. In most recycling processes, the circuit boards would be crushed or pulverized as a first step of these processes. Disassembling, milling, mechanical separation and pyrolysis are typical pretreatment processes.

Understanding the effect of pretreatment processes on crushing of the waste phone's circuit boards can assist the optimization of the recycling processing line. In this paper, the pretreatment processes of disassembling and heating treatment were investigated. The main purpose of this study was to evaluate the effectiveness of crushing process of the waste phone's circuit boards under different pretreatment processes and to determine the proper pretreatment process.

\section{Experimental}

The waste phone's circuit boards used as experimental materials are of various brands and were provided by a waste recovery company in Qingdao, P.R. China. The $900 \mathrm{~g}$ circuit boards were divided into three groups, $300 \mathrm{~g}$ in each group. The circuit boards in first group were without any pretreatment. The electrical components of the circuit boards in second group were manually disassembled before crushing. The circuit boards in third group were heated at $280^{\circ} \mathrm{C}$ for 1 hour.

The crushing experiments were conducted in a hammer crusher with screen mesh $1.5 \mathrm{~mm}$. The 
crushing time is $2.5 \mathrm{~min}$. The crushed circuit boards were sifted in electric vibrating screen with 8 screen meshes $(1.25 \mathrm{~mm}, 0.8 \mathrm{~mm}, 0.6 \mathrm{~mm}, 0.45 \mathrm{~mm}, 0.3 \mathrm{~mm}, 0.15 \mathrm{~mm}, 0.125 \mathrm{~mm}$ and $0.074 \mathrm{~mm})$. The size of the particles in crushed circuit boards was divided into 9 particle size gradations, i.e. $+1.25 \mathrm{~mm}$ (gradation 1), $1.25 \mathrm{~mm}-0.8 \mathrm{~mm}$ (gradation 2), $0.8 \mathrm{~mm}-0.6 \mathrm{~mm}$ (gradation 3), $0.6 \mathrm{~mm}-0.45 \mathrm{~mm}$ (gradation 4), $0.45 \mathrm{~mm}-0.3 \mathrm{~mm}$ (gradation 5 ), $0.3 \mathrm{~mm}-0.15 \mathrm{~mm}$ (gradation 6), $0.15 \mathrm{~mm}-0.125 \mathrm{~mm}$ (gradation 7), $0.125 \mathrm{~mm}-0.074 \mathrm{~mm}$ (gradation 8), $-0.074 \mathrm{~mm}$ (gradation 9). The composition analysis was conducted by x-ray fluorescence spectrometer. The feature of particles was observed by a stereo-microscope (JSZ6, Nanjing Jiangnan Novel Optics Co., Ltd.).

The liberation degree of crushed products $F$ can be expressed as below:

$$
F=\frac{f}{f+\sum f_{i}} \times 100 \%
$$

Where, $f$ is the quantity of single particles of metals in crushed boards; $\Sigma f_{i}$ is the quantity of interlocking particles of metals in crushed boards.

The flow diagram of the experimental process is shown in Figure 1.

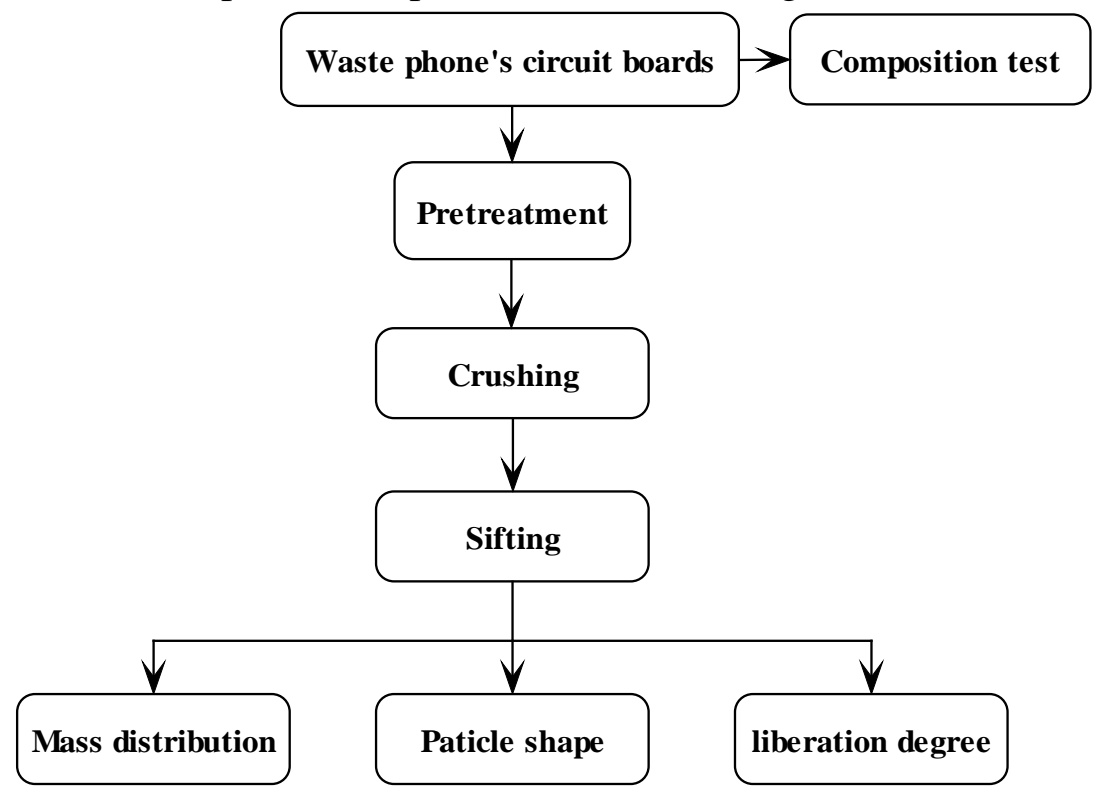

Fig. 1. Flow diagram of the experiments

\section{Results and discussions}

\section{The composition analysis}

The tested metal contents in the waste phone's circuit boards are shown in Table 1. It is shown that the metal contents in phone's circuit boards are higher than that in other circuit boards such as computer motherboards $[5,6]$.

The metals in circuit boards can be grouped into two categories: base metals ( $\mathrm{Cu}, \mathrm{Al}, \mathrm{Fe}$, Sn, et al.), precious and rare metals( $\mathrm{Ab}, \mathrm{Au}, \mathrm{Ti}$, et al.).

Table 1 Average metal content in waste phone's circuit boards

\begin{tabular}{llllllllllll}
\hline Elements & $\mathrm{Cu}$ & $\mathrm{Al}$ & $\mathrm{Fe}$ & $\mathrm{Sn}$ & $\mathrm{Mg}$ & $\mathrm{Ni}$ & $\mathrm{Zn}$ & $\mathrm{Ti}$ & $\mathrm{Pb}$ & $\mathrm{Ag}$ & $\mathrm{Au}$ \\
\hline Content (\%) & 27.7 & 7.37 & 2.54 & 1.91 & 1.36 & 1.25 & 0.50 & 0.42 & 0.39 & 0.29 & 0.05 \\
\hline
\end{tabular}

\section{Mass distribution of crushed boards}

The mass distribution curves of the crushed waste phone's circuit boards are shown in Figure 2. It shows that the mass fraction-particle size gradation curves appear similar "W" shape for three groups. About 45 percent of crushed particles are in the range of particle size above $0.8 \mathrm{~mm}$, and about 5 percent of particles are below $0.074 \mathrm{~mm}$. While the particle size is in $0.074 \mathrm{~mm}-0.8 \mathrm{~mm}$, three curves basically fit the normal distribution. 
For three groups of crushed circuit boards with different pretreatments, the mass of the crushed waste phone's circuit boards is concentrated in gradation 1 and gradation 2 . The proportions of particles bigger than $0.8 \mathrm{~mm}$ are $41 \%, 43.5 \%$ and $45 \%$ in three groups, respectively. The crushed boards in third group have the highest mass in mass distribution $+1.25 \mathrm{~mm}$ and $-0.074 \mathrm{~mm}$ by comparison to the other two groups. For the other two groups, there are no obvious distinctions in mass distributions. So the heating process has the obvious influence on mass distribution of the crushed boards. But the disassembling has almost no effect on crushing effect operation.

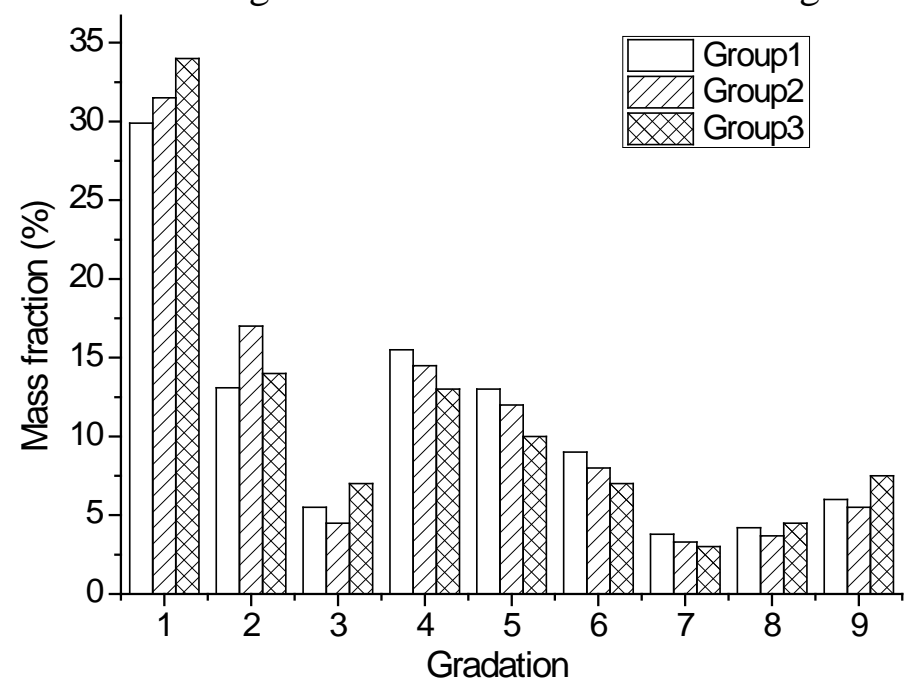

Fig. 2. The mass distribution curves of the crushed boards

\section{Feature of crushed products}

The particles after grading by electric vibrating screen were observed by stereo-microscope. Figure 3 shows the typical feature of crushed products.
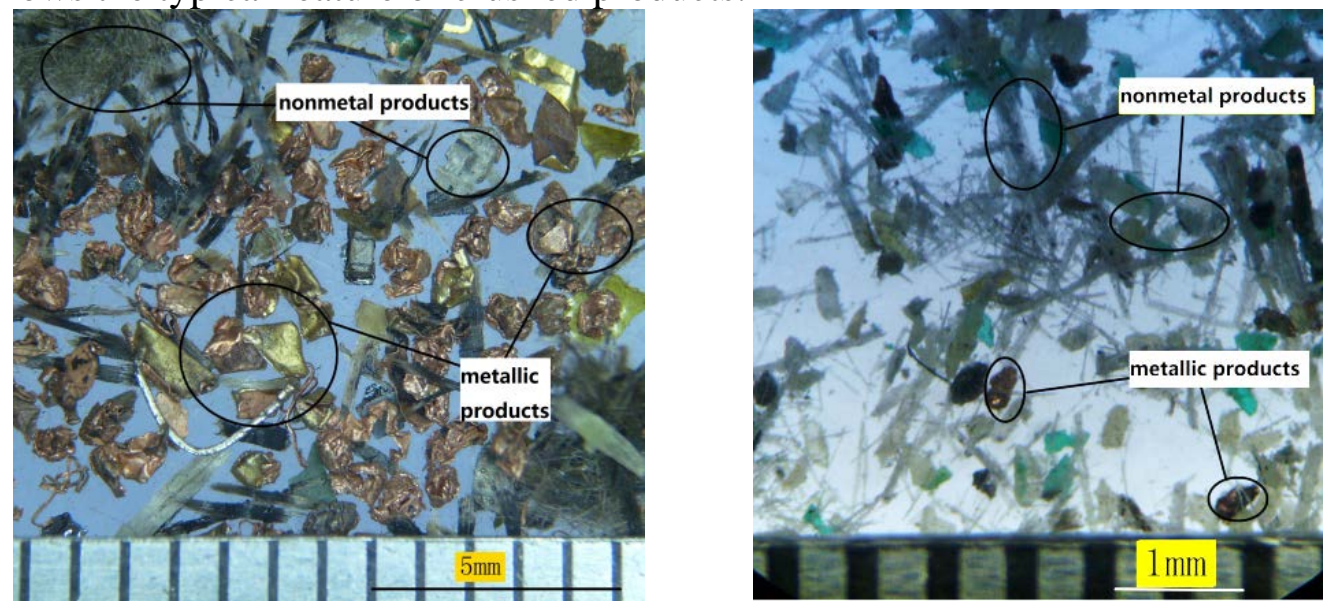

Fig. 3. Typical particle feature of crushed boards

After the circuit boards without disassembling were crushed, the crushing products of metallic packages of the electrical components are mainly concentrated in gradation range of $0.8 \mathrm{~mm}-1.25 \mathrm{~mm}$, and are appear as coarse particles with metallic reflections. The metals on substrate are mainly concentrated in the gradation range of $0.074 \mathrm{~mm}-0.8 \mathrm{~mm}$, and appear as smaller particles and pieces with metallic reflections or even gray powders. The larger crushing products of nonmetals look like translucent flake grain, gray flocculent fibers and fine powders.

The circuit boards after disassembling have the similar crushing products with the circuit boards without disassembling, just have less metal particles in the gradation range of $0.8 \mathrm{~mm}-1.25 \mathrm{~mm}$.

The crushing products of the circuit boards after heating are very different. There are more nonmetallic flocculent fibers in crushing products in the gradation range of $+1.25 \mathrm{~mm}$. In the gradation range of $0.074 \mathrm{~mm}-1.25 \mathrm{~mm}$, the crushing products appear as granular metallic particles and needle-like or powdery metalloid. In the gradation range of $-0.074 \mathrm{~mm}$, the dustlike feature of 
products is most obvious, and there are more products than the other two groups.

\section{Liberation degree}

The crushing process is the mechanical operation of segmentation of solid matter: the surface area is increased without changing the weight. The crushing operation of the circuit boards is to get an entire liberation of metals and nonmetals. The experiments show that the liberation has begun when the size of particles in the crushed boards is smaller than $1.5 \mathrm{~mm}$ and can be divided to two stages. The first stage is the liberation of electrical components on boards, metal case of encapsulation, plastics. The second stage is the liberation of the substrate. The crushing process of the boards is actually the dispersion and liberation of various compositions. The liberation of metals is gradually implemented as the crushing process progresses.

The liberation of circuit boards is the one of the basic conditions for mechanical-physical recycling technology, and is also an important indicator to inspect the crushing effect. According to the Equation 1, the liberation degrees for all gradations in three groups of the crushed boards were measured and calculated. Ten samples were measured in each gradation and the average value was used as the liberation degree. The sampling was performed by the quartering method. If the liberation degree is over 95\%, the metals in the crushed particles are considered entirely liberated.

Under the same pretreatment condition, the finer the crushed particles, the higher the liberation degree of metals. So there may be a critical particle size below which the metals are entirely liberated. After the measures and calculations, the critical particle sizes for three groups were obtained, which are $0.6 \mathrm{~mm}$ for group $1,0.45 \mathrm{~mm}$ for group 2 , and $1.25 \mathrm{~mm}$ for group 3 , respectively. That indicates that the liberation is easiest for circuit boards after heating and is difficult for circuit boards after disassembling.

The boards without pretreatment have many metal cases of encapsulation and small electrical components, which can be turned into granular particles under the effect of impact and knead after separating from surface on substrate. These hard particles can help to crush and separate various composition of substrate. The crushing process of the boards after disassembling pretreatment is lack of the effect of these hard particles, so the liberation is more difficult. Although there is no the effect of these hard particles in the crushing process of the boards after heating pretreatment, the substrate has been pyrolyzed and carbonized to some extent and the bonding strength among the ingredients. So the boards can be get a higher liberation degree and easier liberation effect.

Therefore, there are two pretreatment options for crushing process of the waste phone's circuit boards. One is to directly crush the boards without any pretreatment, and the other is to apply appropriate heating treatment. However, the heating process of circuit boards not only consumes more energy and needs heating devices, but also releases harmful fumes. So the heating treatment is rarely used unless absolutely necessary.

\section{Conclusion}

The crushing effect of the waste phone's circuit boards under three pretreatment processes (without pretreatment, disassembling electrical components, heating treatment) was investigated in this paper. It is found that the heating process has the obvious influence on mass distribution of the crushed boards and disassembling has almost no effect on crushing effect. The metals in crushing products appear as granular metallic particles or metallic pieces, but the nonmetals appear as needle-like flocculent fibers, translucent flake grain or fine powders. The circuit boards after disassembling have the similar crushing products but less metal particles in the gradation range of $0.8 \mathrm{~mm}-1.25 \mathrm{~mm}$ in comparison with the circuit boards without pretreatment. After heat treatment, the crushing products of boards have more needle-like in the biggest gradation range and dustlike in the smallest gradation range. The investigation of liberation degrees indicates that the liberation is easiest for circuit boards after heating and is difficult for circuit boards after disassembling. Considering the impact of environment and investment, the waste phone's circuit boards can be directly crushed without disassembling and heating treatment. 


\section{Acknowledgement}

The authors are thankful for the financial support of Project for Recycling of Non-ferrous Metals from material science and engineering school, Lanzhou University of Technology.

\section{References}

[1] Vasile C., Brebu M.A., Totolin M., Yanik J., Karayildirim T., Darie H.. Feedstock recycling from the printed circuit boards of used computers. Energy Fuel, 2008 22:1658-1665.

[2] Sohaili J., Muniyandi K.S., Mohamed S.S.. A review on printed circuit boards waste recycling technologies and re-use of recovered nonmetallic materials. International Journal of Scientific \& Engineering Research, 20123 (2):138-144.

[3] Eswaraiah C., Kavitha T., Vidyasagar S., Narayanan S.S.. Classification of metals and plastics from printed cir-cuit boards (PCB) using air classifier. Chemical Engineering and Processing, 2008 47:565-576.

[4] Sohaili J., Muniyandi K.S., Mohamed S.S.. A review on potential reuse of recovered nonmetallic printed circuit board waste. Journal of Emerging Trends in Engineering and Applied Sciences, 20112 (6):946-951.

[5] Waldir A. B., Renata A. F., Valdelis F. de A.. Charac-terization of Printed Circuit Boards for Metal and Energy Recovery after Milling and Mechanical Separation. Materials, 2014 7:4555-4566.

[6] Jae-Min Y., Jinki J., Kyoungkeun Y., Jae-chun L. \& Wonbaek K.. Enrichment of the metallic components from waste printed circuit boards by a mechanical separation process using a stamp mill. Waste Management, 2009 29:1132-1137. 